\title{
8
}

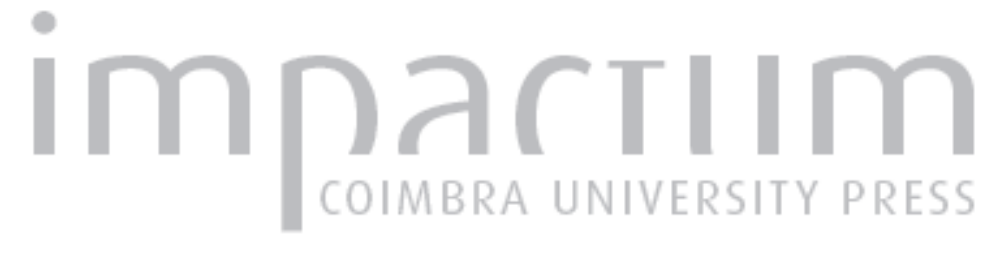

\section{Para uma leitura comparada da realeza divina no Hatti, em Ugarit e em Hesíodo}

Autor(es): $\quad$ Galhano, João Paulo

Publicado por: Centro de História da Universidade de Lisboa

URL persistente:

URI:http://hdl.handle.net/10316.2/23600

DOI:

DOI:http://dx.doi.org/10.14195/0871-9527_21_7

Accessed : $\quad$ 26-Apr-2023 12:10:39

A navegação consulta e descarregamento dos títulos inseridos nas Bibliotecas Digitais UC Digitalis, UC Pombalina e UC Impactum, pressupõem a aceitação plena e sem reservas dos Termos e Condições de Uso destas Bibliotecas Digitais, disponíveis em https://digitalis.uc.pt/pt-pt/termos.

Conforme exposto nos referidos Termos e Condições de Uso, o descarregamento de títulos de acesso restrito requer uma licença válida de autorização devendo o utilizador aceder ao(s) documento(s) a partir de um endereço de IP da instituição detentora da supramencionada licença.

Ao utilizador é apenas permitido o descarregamento para uso pessoal, pelo que o emprego do(s) título(s) descarregado(s) para outro fim, designadamente comercial, carece de autorização do respetivo autor ou editor da obra.

Na medida em que todas as obras da UC Digitalis se encontram protegidas pelo Código do Direito de Autor e Direitos Conexos e demais legislação aplicável, toda a cópia, parcial ou total, deste documento, nos casos em que é legalmente admitida, deverá conter ou fazer-se acompanhar por este aviso.

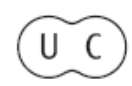



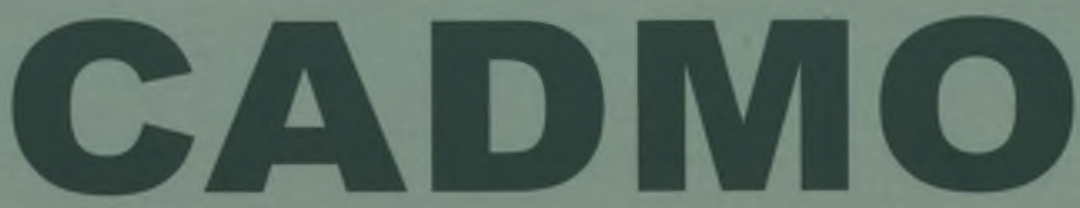

Revista de História Antiga

\author{
Centro de História \\ da Universidade de Lisboa
}

\title{
21
}

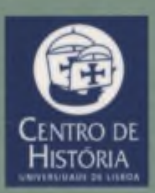

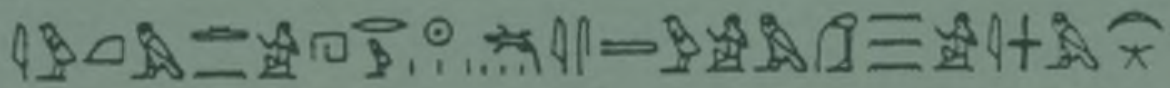

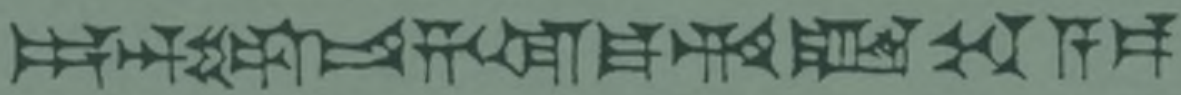

MHNIN AEI $\Delta \mathrm{E} \Theta \mathrm{EA}$ ПH$\Lambda \mathrm{HIA} \triangle \mathrm{E} \Omega$ 


\title{
PARA UMA LEITURA COMPARADA DA REALEZA DIVINA NO HATTI, EM UGARIT E EM HESÍODO
}

\author{
JOÃO PAULO GALHANO \\ Universidade de Lisboa \\ jptsgalhano@gmail.com
}

"Que é então a história comparada? Uma verdade particular da história? Um método? Não, é uma heurística."

Paul Veyne ${ }^{1}$

\section{Resumo}

Hesíodo sublinha a incontestabilidade da realeza de Zeus, não obstante as narrativas mitológicas hurritas concederem alguma fraqueza a Tešub. Zeus surge associado à justiça em diversos planos e episódios, mas as funções do deus Sol hático subjazem a parte da actividade de Zeus, enquanto omnisciente dispensador de justiça, ainda que a realeza divina não tenha expressão directa nos mitos anatólicos antigos. A Teogonia, enquanto mito de soberania, valoriza o carácter ordenador de Zeus, o que tem paralelo na atribuição de handātar ao rei divino ideal hurrita. Em Ugarit, o pouco explorado topos da justiça divina foi associado à realeza de Ba'lu e ao principado de Yammu. O modelo familiar patriarcal subjaz aos mitos hurritas e a Hesíodo, tendo capacidade para explicar a aparente realeza dual da mitologia de Ugarit. A suposta bicefalia divina de Ugarit evidencia um processo de transição religiosa, sem afastamento efectivo da supremacia de llu.

Palavras-chave: realeza divina; justiça; paternidade; Hatti; Ugarit; Hesíodo.

\begin{abstract}
Hesiod emphasizes the indisputability of Zeus' kingship, despite hurrian mythological narratives allows some weakness to Tešub. Zeus appears
\end{abstract}


associated with justice in several ways and episodes, but the hattic Sun god functions underlay part of Zeus' activity, while omniscient dispenser of justice, without direct expression of divine kingship in ancient anatolic myths. Theogony, as a sovereignty myth, gives special prominence to Zeus' ordaining character, with paralel in the assignment of handātar to the hurrian ideal divine king. In Ugarit, the not so much explored topos of divine justice was connected to Ba'lu's kingship and to Yammu's principality. The patriarchal familiar model underlies hurrian myths and Hesiod, having explaining ability to the apparent dual kingship of Ugarit's mythology. The pretendend divine bicephaly of Ugarit reveals a process of religious transition, without effective clearance of llu's supremacy.

Keywords: divine kingship; justice; fatherhood; Hatti; Ugarit; Hesiod.

O tópico da realeza divina, assim se entendendo aquela concretizada num rei de deuses ${ }^{2}$, tem veemente expressão em diversas mitologias antigas, constituindo um lugar narrativo de intercepção de tradições culturais oriundas de variadas matrizes próximo e médio orientais. No domínio grego, Hesíodo exemplifica o modo como esses moldes podem ser apropriados em tradições posteriores. A análise comparada do modelo hesiódico com as tradições hática e ugarítica permite observar o modo como as concepções associadas à realeza divina puderam ser transmitidas do final do Bronze Antigo para a Idade do Ferro helénica, bem como considerar algumas idiossincrasias dos mitos anatólicos e ugaritianos, face à formação hesiódica patente na Teogonia e em Trabalhos e Dias. Nesse sentido, a análise aqui proposta pode ser vista como um contributo para a mais larga questão da influência oriental na Grécia Arcaica, ou então como aproximação à investigação histórica das idiossincrasias viventes nos textos legados por Háticos, Ugaritianos e Hesíodo.

A glorificação de Zeus surge como propósito de Hesíodo logo no início da Teogonia: aquele deus «pai dos deuses e dos homens, / ele que entre os deuses detém o primeiro e maior poder ${ }^{3}$, logo aqui se acentuando o exclusivismo do mando do rei divino, lugar único e indisputável. A subserviência dos entes divinos a Zeus, o rei dos deuses, surge bem vincada, por exemplo, no mito de Perseu e Medusa: logo após ter nascido e, portanto, respondendo a uma vocação natural, Pégaso serve Zeus, antes mesmo da narração hesiódica ter desenvolvido todo o mito de sucessão ${ }^{4}$. O próprio modo de referir o agente da morte de Gérion por "força de Héracles" ${ }^{5} \mathrm{e}$ não simplesmente "Héracles", sendo este um filho de Zeus, mostra como Hesíodo, por detrás do mito de Héracles e Gérion ${ }^{6}$, pretende valorizar o poder de Zeus, de quem Héracles recebeu a força. A simples valorização 
de Héracles, por exemplo no mito de Héracles e dos filhos de Tífon ${ }^{7}$, serve também como enaltecimento indirecto de Zeus, por via da ascendência daquele herói ${ }^{8}$. A caracterização hesiódica de Zeus recusa-se mesmo a descobrir qualquer elemento de fraqueza no rei divino, situação sem paralelo nos textos hurritas, dado que, n'O Canto de Ullikummi, o rei divino, Tešub, não obstante ser o supremo poder nos céus, tem receio de ser incapaz de vencer o inimigo, expressando o seu desespero através do choro ${ }^{9}$.

Logo após chegar a rei divino, Zeus exerce o seu poder de garante da justiça, castigando os filhos de Clímene ${ }^{10}$ : a Menécio envia-o para o Érebo e a Prometeu castiga-lo-á da forma sobejamente conhecida. Tanto na Teogonia como em Trabalhos e Dias, Hesíodo associa Zeus ao exercício da justiça, cumprida não só sobre os deuses mas também junto dos homens, os quais, não obstante, estão dependentes da arbitrária vontade divina, para o bem e para o mal ${ }^{11}$. Para Hesíodo, Zeus proporcionou a justiça aos homens para que eles não vivessem em permanente estado de guerra uns com os outros, comportando-se como animais ${ }^{12}$. A insistência de Hesíodo na associação de Zeus à justiça, além de possível influência homérica, admitindo-se criação anterior das obras homéricas, ou pelo menos da llíada, em relação às obras de Hesíodo, tem fundamento na própria situação do poeta, dado que a sua condição de camponês afastado dos favores da aristocracia local impelia-o à defesa da justiça, essa mesma que os reis locais deveriam observar, visto terem-na recebido do supremo deus grego. Para Hesíodo, Zeus é assim uma última instância de apelo à justiça, exercido por meio da sua poesia inspirada pelas Musas, justamente filhas de Zeus ${ }^{13}$. Logo na abertura de Trabalhos e Dias, o poeta invoca as Musas para que cantem em hinos o pai Zeus que facilmente abaixa o soberbo, endireita o tortuoso e harmoniza as sentenças com justiça ${ }^{14}$. A justiça divina foi até a causa última do fim da Idade de Prata, visto que Zeus fez desaparecer os seres deste tempo mítico em consequência da sua falta de culto aos imortais ${ }^{15}$. De forma semelhante, Zeus destruirá os homens da Idade do Ferro, a de Hesíodo, depois do breve terrível período em que justiça reside apenas na força ${ }^{16}$. A justiça de Zeus é também exercida entre e sobre os deuses, por exemplo, com a entrega de Perséfone a sua mãe, após ter sido raptada por Hades ${ }^{17}$. Aliás, sempre que há disputa entre os deuses, é Zeus quem envia Íris em busca do juramento dos deuses num cântaro de ouro e, quando uma divindade comete perjúrio depois de derramar a água do rio sagrado, fica um ano sem vida, envolto num coma cruel, em resultado do seu crime ${ }^{18}: 0$ agente da punição, para além do abstracto juramento, é o supremo deus grego. Pode até ver-se que a associação de Zeus à justiça se estabelece 
pela relação filial, pois, após a união de Zeus a Témis, nascem as Horas, a Paz, a Eunomia e a própria Justiça deificada ${ }^{19}$.

Apesar da proximidade tipológica de Zeus ao hurrita Tešub, o rei divino grego, neste particular aspecto de juiz junto de deuses e homens, assume funções semelhantes às do deus Sol hático (o que não significa que Tešub nunca tenha sido concebido como instância de apelo à justiç $\left.\mathrm{a}^{20}\right)$. Apelidado de Grande deus Sol ou de deus Sol dos Deuses ${ }^{21}$, esta divindade hática tem como função essencial fazer justiça entre os homens, razão pela qual surge qualificado como rei dos homens ${ }^{22}$, sem nunca chegar a essa qualificação inter pares, i.e., entre deuses. $O$ deus Sol é tido como rei do Universo em algumas orações no mesmo sentido em que o rei terreno o pretende ser, enquanto juiz de todo o seu reino ${ }^{23}$. Com tal qualificação real, estranha aos mitos anatólicos antigos e mesmo às narrativas mitológicas hurritas, o rei pretende sancionar as suas funções judiciais, legitimando-se através do deus Sol. A associação da realeza ao deus Sol surge mesmo reflectida na titulatura real hática ¿UTUšl, habitualmente traduzida por «minha majestade» ${ }^{24}$.

Contudo, a ideia de realeza divina é estranha aos mitos anatólicos antigos - assim se entendendo os mitos de divindades ausentes e o Mito de Illuyanka: há sim superioridade de algumas divindades, que se distinguem pela sua importância ou função: a deusa Sol de Arinna, o deus Tempestade, Hannabanna e o deus Sol enquanto organizador do banquete divino. $\mathrm{Na}$ abertura da estória Appu e os Seus Dois Filhos ${ }^{25}$, a não nomeada divindade que vinga os homens justos e derruba os injustos, como se fossem árvores, é decerto o deus Sol, o deus hático da justiça, similar não só ao grego Zeus mas também ao babilónio Šamaš. Aliás, a expressão "abaixar os soberbos» de Hesíodo ${ }^{26}$ é bastante semelhante ao "derrubar os injustos" da estória de $\mathrm{Appu}^{27}$. Esta função de juiz divino surge naturalmente atribuída ao deus Sol, na medida em que o sol, no seu aparente curso diário, observa o mundo terreno a uma altura ou distância imparcial, tudo vendo e iluminando ${ }^{28}$. O próprio olho de Zeus tudo vê e tudo sabe $^{29} \mathrm{e}$, até certo ponto, não é possível enganá-lo ou iludi-lo $0^{30}$ : há assim uma certa omnisciência divina atribuída expressamente a Zeus e apenas tacitamente ao deus Sol hático, tornando a expressão daquela pansofia divina uma idiossincrasia grega, no âmbito dos textos em investigação. Para mais, se a concepção de justiça divina não é originalmente grega, tendo antecedentes não só nos textos anatólicos como também noutros ${ }^{31}$, a deificação da própria Justiça, uma abstracção divinizada, surge como particularidade grega, ela própria uma filha de Zeus $^{32}$ e uma sua determinação ${ }^{33}$. 
O papel de Zeus, uma vez alçado ao comando real divino, não se esgota na sua função judicial: alarga-se de forma significativa à sua tarefa de distribuidor de honras e competências, à sua definição. A Teogonia, enquanto canto de celebração de Zeus, pretende, desde logo, narrar a distribuição dessas competências, a ocupação do espaço divino do poder, como é dito imediatamente antes da narração da cosmogonia hesiódica ${ }^{34}$. Após o combate de Zeus com Tífon e o subsequente estabelecimento de Zeus no trono divino para todo o sempre, o rei divino grego, num primeiro acto de governo divino, atribui honras ${ }^{35}$ aos imortais ${ }^{36}$. Assim, a luta pela sucessão divina não é um conjunto de episódios de violência gratuita, mas o caminho em direcção ao triunfo da justiça e da ordem ${ }^{37}$ : a Teogonia surge assim como um mito de soberania ${ }^{38}$, mostrando como a ordem resultou, não só das vitórias de Zeus, mas também da sua sábia repartição das competências divinas. Comparando com outra área mitológica, a valorização do papel interventor e ordenador de Zeus tem paralelo na descrição hurrita das características que tornam uma grande divindade habilitável a rei, dado que, além do mal, palavra nesita para designar capacidade guerreira, do uso da palavra ou, diríamos nós, da capacidade de oratória consequente, e da sabedoria, o rei divino possui bandātar, palavra nesita para denotar o poder de um deus para controlar o curso dos acontecimentos ${ }^{39}$.

No domínio ugarítico, o tema da justiça exercida por deuses parece ter ocorrência mais rara ${ }^{40}$. O topos da justiça parece encontrar-se associado tanto a Ba'lu, dado que encontramos entre os seus epítetos o de «nosso juiz " ${ }^{41}$, como a Yammu, recorrentemente chamado "juiz Naharu " ${ }^{42}$. O caso de Ba'lu poderia parecer, à primeira vista, paralelo à situação de Zeus, em virtude de ambas as divindades serem celestes e estarem assim em relação com a justiça, contudo, aquele epíteto de Ba'lu parece remeter apenas para a realeza de Ba'lu, dado o paralelismo da pronominação possessiva de Ba'lu no caso de "nosso juiz» e de "nosso rei», também este um epíteto de Ba'lu ${ }^{43}$. No caso de Yammu, o mar divinizado de Ugarit, o epíteto "juiz Naharu» pode estar relacionado com a tradição mesopotâmica do ordálio fluvial, no âmbito do qual se cria que o deus-rio díD ou đÍD.LÚ.RU.GÚ julgava os acusados ${ }^{44}$. A estar correcta tal interpretação, estaria aqui uma demarcação entre os territórios mitológicos grego e hático, onde a justiça está associada ao deus celeste (Zeus ou o deus Sol), e a região semítico-ugarítica, em que a função de justiça estaria acometida a um deus marinho e inferior (Yammu), não obstante, no domínio grego, a água do rio sagrado também estar presente no julgamento dos imortais, levados à justiça de Zeus após terem cometido perjúrio ${ }^{45}$. 
Ainda que tal leitura seja possivel, não pode deixar de se assinalar o facto de todas as ocorrências daquele epíteto de Yammu, o de «juiz Naharu", se darem no período compreendido entre a designação de Yammu como rei, por llu, e a sua destruição por parte de Ba'lu, podendo tal circunstância significar que também no caso de Yammu estamos em presença do uso do vocábulo tpț, «juiz», com uma semântica próxima de $m / k$, "rei", como acontece no caso de Ba'lu, ainda que Yammu não seja nunca designado rei, mas apenas "príncipe Yammu» ${ }^{46} \mathrm{e}$ "Amado de Ilu ${ }^{47}$, sendo também relevante que o epíteto "príncipe Yammu» esteja quase sempre associado ao de «juiz Naharu». Assim, parece clara a associação ugarítica do rei divino em exercício à justiça, seja ele qual for, o que, no caso de llu, o rei supremo do panteão ugarítico, se poderá entrever no seu papel de moderador das lutas divinas, em resultado da busca do equilíbrio entre forças antagónicas ${ }^{48}$, ainda que as inquietações mitológicas ugaríticas não tenham reflectido tão largamente sobre o topos da justiça como Hesíodo o fez.

As Musas do Hélicon dançam em volta do altar do poderoso filho de Crono ${ }^{49}$, cedo se referindo Zeus pela sua ascendência crónida, em clara valorização do vector paternal e da via belicosa no assentamento do poder divino ${ }^{50}$. De seguida, o mito hesiódico de sucessão narra como Úrano foi substituído no poder por Crono e como este, por sua vez, foi afastado por Zeus, um deus da geração seguinte: Úrano surge aí como a primeira figura paternal, nunca qualificado de rei divino - nem ánax, nem basileús: a sua superioridade decorre exclusivamente do seu estatuto primipaternal. Também Zeus, o mais novo dos Crónidas, adopta frequentemente o epíteto de "pai dos deuses e dos homens" ${ }^{51}$ e de "Zeus Crónida» ${ }^{52}$, assim se demonstrando haver uma valorização da paternidade na esfera divina, ou seja, a adopção mitológica de um modelo familiar patriarcal em Hesíodo, situação que é, afinal, característica comum às religiões indo-europeias ${ }^{53}$, em que $o$ chefe dos deuses surge associado à paternidade e ao céu ${ }^{54}$. Não obstante, aquele epíteto de "pai dos deuses e dos homens" pode ser lido, não como significante de precedência procriadora, mas como qualificativo enquadrado na responsabilidade de Zeus pela existência humana e divina, enquanto dispensador de justiça a deuses e homens ${ }^{55}$.

No texto hurrita intitulado O Canto de Prata, também o deus Prata, inicialmente qualificado de órfão ${ }^{56}$, fica envergonhado por ser reputado como tal ${ }^{57}$, assim se descobrindo a importância da ideia de paternidade e sobretudo de família no plano hurrita. O episódio referido, especialmente a resposta da mãe de Prata ao seu filho, que inclui uma descrição familiar alargada, sublinha a importância da paternidade e da linhagem familiar 
para a afirmação "social» do deus no mundo divino. Aliás, naquele mesmo episódio d'O Canto de Prata, o conselho da mãe de Prata sublinha o temor reverencial que o filho deve ter perante o seu pai, mas não perante o rei em exercício (Tešub), estranhamente qualificado como irmão de Prata, quiçá porque também Prata pretende ascender ao trono então ocupado por Tešub. Ou seja, neste passo d'O Canto de Prata, o poder paternal parece sobrepôr-se até ao poder real.

A preponderância das relações familiares, com especial ênfase no papel do pai, n'O Ciclo de Kumarbi, encontra-se ainda no facto de, n'O Canto de Prata, Tešub medir as suas próprias capacidades com as do pai de Prata, após este conseguir temporariamente a realeza ${ }^{58}$. Também n'O Canto de Hedammu se pressente a importância do instituto da paternidade no estabelecimento das relações de poder entre as divindades, especialmente quando Kumarbi, o rei deposto, num período em que tudo indica que Tešub está no poder, pretende realizar uma aliança política com o deus Mar e continua a intitular-se "pai dos deuses", como se quisesse manter o seu ascendente através desta titulatura ${ }^{59}$. Aliás, Kumarbi volta a recorrer a esta titulatura n'O Canto de Ullikummi60. Note-se de passagem que, enquanto pai dos deuses na mitologia hurrita, Kumarbi pode ser considerado equivalente de Enlil na mitologia sumero-babilónia ${ }^{61}$.

No domínio ugarítico, as relações pai-filho podem talvez explicar a aparente bicefalia divina de Ba'lu e llu, numa aparente «mitologia dualística» ${ }^{62}$. Numa primeira leitura, Ba'lu parece ser o único competidor válido de llu em todo o Ciclo de Ba $/ \mathrm{u}^{63}$, ainda que o seu afastamento inicial do trono divino, logo no início do mito da Luta entre Ba'lu e Yammu, possa ter sido motivado por uma revolta anterior contra llu ${ }^{64}$ ou, por outro lado, constituir ditame de llu na sequência de algum confronto entre Ba'lu e os outros deuses ${ }^{65}$. A insubmissão perante llu regista-se logo na imprecação que Ba'lu dirige a Yammu, após saber do futuro reinado deste senhor dos mares ${ }^{66}$, não sendo mais do que a continuação daquele orgulho e altivez mostrados por Ba'lu $a b$ initio ${ }^{67}$. As aspirações de Ba'lu à posição de mais alta divindade do panteão, no âmbito mitológico, são visíveis depois no mito O Palácio de Ba'lu, quando ele mesmo diz conhecer exemplarmente o raio, o seu instrumento divino que os céus não conhecem, nem os homens compreendem ${ }^{68}$. A associação climatérica da trovoada à chuva, na Síria do Norte, pode estar na base da importância de Ba'lu para os Ugaritianos, assim se explicando que, no monólogo final de Ba'lu, do mito O Palácio de Ba'lu, esta divindade se arrogue da posição de "único que reinará sobre os deuses, e que deveras engordará deuses e homens"69. Tal afirmação apenas expõe o âmbito da realeza de Ba'lu, apoiada na 
sua capacidade de interferir na esfera divina, humana e natural: a realeza de Ba'lu permite assim a inteligibilidade religiosa de toda a realidade ${ }^{70}$.

O mito O Palácio de Ba'lu pode ser considerado um «mitema de afirmação", cuja função essencial seria assegurar o protagonismo de Ba'lu na cena mitológica ugarítica, assim se compreendendo a estória da abertura da janela no palácio de Ballu naquele mito ${ }^{71}$, como possibilitação da manifestação divina de Ba'lu, a chuva e o trovão. A posição hegemónica de Ba'lu lê-se no seu epíteto de "poderoso " ${ }^{72}$ e até no seu próprio nome, cujo significado, "senhor", é possível abreviatura de "senhor da terra»" designação genérica do deus tempestade entre os Semitas da Síria após o II milénio a. C. Aliás, na teofania de Ba'lu a Daniilu da Epopeia de Aqhatu74, Ba'lu surge em posição privilegiada em relação a llu, parecendo ser essa a intenção do escriba ugarítico llimilku: Ba'lu ordena a llu que bendiga Daniilu a fim de que este possa ter filhos, ordem acatada e executada por Ilu tal como prescrita por Ba'lu 75 . Esta posição relativa pode, no entanto, revelar uma evolução do religioso ugarítico, em transição de um modelo de superioridade llu, visível por exemplo no Ciclo de Ba'lu, para outro em que Ba'lu levaria vantagem sobre todas as divindades, incluindo sobre Ilu, se, em tal caso, se admitir criação posterior da Epopeia de Aqhatu, ou até mesmo da Epopeia de Kirta, na qual também Ba'lu ordena a llu que bendiga Kirta ${ }^{76}$, ainda que, em todo o caso, aquela substituição de llu por Ba'lu não tenha chegado a concretizar-se substantivamente no decurso da história ugarítica, quiçá em resultado do final abrupto da cidade de Ugarit, aquando da chegada dos Povos do Mar.

A cronologia relativa dos textos mitológicos de Ugarit torna-se ainda mais candente se lembrarmos que na Epopeia de Kirta o nome de llu precede sempre o de Ba'lu, ao passo que na Epopeia de Aqhatu sucede sempre o contrário, o que pode revelar o crescendo da importância de Ba'lu no religioso de Ugarit ${ }^{77}$. A preponderância de llu na Epopeia de Kirta pode ser observada noutras situações: quando Kirta se qualifica como "servo de llu» ${ }^{78}$, sem qualquer referência a Ba'lu; quando Udumu, cidade do rei Pabilu, é qualificada de "dom de Ilu»"79; quando Ilimilku atribui a llu a capacidade para curar Kirta, depois de llu ter perguntado aos deuses quem conseguiria expurgar a enfermidade de Kirta sem obter qualquer resposta ${ }^{80}$; na atribuição do epíteto de "Touro" a llu, com ocorrência também no mito O Palácio de Ba / $u^{81}$; ou até mesmo na insistência da associação do epíteto de "pai do homem» ${ }^{82}$ a llu, ainda que com paralelo noutros textos ugaríticos na versão de "criador das criaturas" ${ }^{83}$.

Em todo o caso, a relação de llu com Ba'lu tem a marca da instabilidade: inicialmente, Ilu apoia Yammu em desfavor de Ba'lu ${ }^{84}$, mas depois, 
uma vez derrotado Yammu, concede-lhe autorização para construir um palácio ${ }^{85}$. A relação entre Ba'lu e llu foi já diversamente interpretada: de certo ponto de vista, o facto de Ba'lu lutar pelo trono divino e de llu concretizar uma instância de poder mais distante poderia caracterizar llu como um deus otiosus, uma divindade em repouso após a sua criação do mundo ${ }^{86}$; noutra leitura, o Ciclo de Balu narraria a história da deposição de llu pelos seus filhos, em que Ba'lu tomaria o céu, Yammu o mar e Môtu o mundo inferior ${ }^{87}$. Foi até já suposto que llu foi não só derrotado por Ba'lu como também castrado por ele, colocando llu numa posição impotente e justificativa da criação de opositores a Ba'llu ${ }^{88}$, leitura esta que decorre de analogias um tanto prisioneiras do Ciclo de Kumarb ${ }^{\beta 9}$. Para outros, não há nenhuma contradição entre a realeza de Ba'lu e a de llu, dada a sua complementaridade: llu, sage e idoso, é complementado por Ba'lu, o deus jovem e ardoroso, em que o primeiro serve de moderador à violência dos combates entre o segundo e os seus oponentes, Yammu e Môtu ${ }^{90}$. A superior posição de llu assenta assim também na estratigrafia do saber divino, visível, por exemplo, quando llu se dispõe a revelar algo a Kôtaru que as multidões da terra não compreendem ${ }^{91}$.

Não obstante, a posição relativa de llu e Ba'lu está patente também nos epítetos de llu: o de "Pai de anos", habitualmente associado ao de "Rei» ${ }^{92}$, ou simplesmente "Pai ${ }^{93}$ e "nosso $\mathrm{Pai}$ »" , assim se valorizando a paternidade também nos textos ugaríticos, de forma similar ao ocorrido em Hesíodo e nos mitos anatólicos, em que o modelo patriarcal é igualmente dominante e subjacente ${ }^{95}$. Charles Virolleaud, autor da editio princeps de vários textos ugaríticos, associou llu ao hesiódico Crono em virtude do epíteto de "Pai de Anos" remeter para uma temporalidade da entidade divina comparável à de Crono, dada a associação, posterior a Hesíodo, de Krónos a Chrónos, por similaridade fonética daqueles dois entes divinos gregos ${ }^{96}$. Na Epopeia de Aqhatu, pode apreciar-se o tom paternal da resposta de llu a 'Anatu, após a ameaça desta de quebrar a cabeça a llu, coisa que llu releva como acto pueril ou adolescente ${ }^{97}$. Por seu lado, Ba'lu é apresentado em diversos loci ugaríticos como «filho de Dagānu "98 um seu exclusivo epíteto, sendo designado uma vez "rebento de Dagānu "99 , ambos os nomes ocorrendo em posposição a Ba'lu. Tal situação parece estar em contradição com o epíteto de "filho de llu», igualmente ligado a Ba'lu, e com os epítetos de "criador das criaturas", associado a llu ${ }^{100}$, e de "criadora dos deuses", atribuído a Atiratu ${ }^{101}$. Foi já proposto que Dagānu fosse outro nome de llu, chegando até a ser identificado com o hurrita Kumarbi, o que equivaleria a dizer que Dagānu foi divindade disseminada fora de Ugarit, sendo o epíteto baliano «filho de 
Dagānu " o indício da origem estrangeira de $\mathrm{Ba}^{\prime} l u^{102}$. Tal interpretação não colide com o facto da filiação de Ba'lu em llu ser meramente convencional, colocando-se Ba'lu na mesma posição de todos os outros deuses.

A hegemonia de llu é confirmada não só no facto da sua supremacia nunca ser contestada, o que não acontece com Ba'lu, mas também porque assenta nos seus poderes de decisão acerca da hierarquização divina, sendo a designação de Yammu o exemplo mais flagrante, podendo também, nesse sentido, apontar-se a designação de Ba'lu para o conselho dos deuses por decisão de $\mathrm{ll}^{103}$. Esta capacidade de llu ocorre também no mitema Combate de Ballu e os Deuses do Deserto, em que os opositores de Ba'lu são nomeados também por $\| l^{104}$, fazendo daquele mito uma teomaquia promovida pelo «rei, pai de anos» do divino ugarítico ${ }^{105}$. Não obstante, a superioridade hierárquica de llu em relação a Ba'lu não implica que estas duas divindades sejam antagónicas, apenas actuando em planos distintos, reservando-se a llu o papel de criador dos deuses e dos homens e a Ba'lu um papel mais activo no quotidiano, regulando a chuva e impondo limites ao mar (sc. Yammu), preocupação natural de um povo costeiro como o de Ugarit.

Tanto Ba'lu como llu aparecem nos textos ugaríticos associados à realeza, llu como «o rei» ${ }^{106}$ e Ba'lu como "o nosso rei» ${ }^{107}$, ainda que este último deus nunca apareça nos textos ugaríticos como deus supremo ${ }^{108}$. O reflexo bíblico da importância de Ba'lu na religião de Canaã não impede de ver Ba'lu como entidade secundária do panteão ugarítico ${ }^{109}$, um actuante superior do panteão, mas em plano distinto do de llu. Nem o próprio uso do epíteto "rei» pode servir de determinador exclusivo da realeza suprema dos deuses, dado que também Harbabbu é chamado “rei da fruta do Verão» e "rei da época das núpcias» ${ }^{110}$, sem que, por isso, Harbabbu seja rei de deuses, quando muito rei entre deuses, no seu específico domínio. Em todo o caso, se a tensão aporética entre a realeza de Ba'lu e a de llu não parece ser negligenciável, a consecução da realeza em vários planos divinos, no domínio mitológico, de que resulta alguma autonomia dos divinos perante os humanos, pode considerar-se idiossincrasia ugarítica, não exposta em tão alarmante modalidade nem em Hesíodo, nem no Hatti, lugares mitológicos em que a realeza tende mais à unicidade do mando de Zeus ou de Tešub ${ }^{111}$.

A ênfase na unicidade do mando divino n'O Ciclo de Kumarbi observase também com a associação da má realeza divina, assim se entendendo a realeza de divindade diferente de Tešub, ao tema da abundância desmesurada, que surge associada à divindade protectora 'LAMMA: durante 0 seu breve reinado nos céus, os lobos eram pacíficos e a cerveja e o vinho 
corriam pelos vales das montanhas ${ }^{112}$, porém, esta excessiva abundância concedida aos homens pela divindade 'LAMMA torna-se perniciosa, visto que, nessas condições, os homens se tornam relaxados em relação às suas obrigações perante os deuses ${ }^{113}$. Só a reposição de Tešub no poder devolve a situação de equilíbrio perdido. A seu tempo, para Hesíodo, a abundância, figurada em riqueza ou Pluto, é filha de Deméter e lásion, não descende de Zeus mas da sua irmã Deméter ${ }^{114}$, filha de Reia e de Crono ${ }^{115}$ e neta de Úrano e de Gaia, não tendo, contudo, tal conotação negativa, até porque Zeus, se quisesse, poderia conceder riquezas infinitas: não o faz porque o mito diz que elas devem ser conseguidas com trabalho ${ }^{116}$. Assim, de certa forma, a limitação da abundância está associada ao rei divino, tanto no Hatti como em Hesíodo.

\section{Notas}

(1) VEYNE, 2008: 138.

(2) Não abordaremos aqui o especial estatuto dos reis semi-divinos ou divinizados, patente tanto na literatura de Ugarit, com o caso de Kirta ou até, possivelmente, Daniilu, como no Hatti, visto que os seus reis, ao morrerem, se "tornam deuses". A ênfase da investigação coloca-se aqui na figura do rei dos deuses e não nos reis que se tornam deuses.

(3) Th. 43-48; gr. fértatós esti theôn kártei te mégistos.

(4) Th. 277-286.

(5) Grego: Biê Êraklêeiê.

(6) Th. 286-294.

(7) Th. 306-318.

(8) Nova referência à "força de Héracles" em Th. 327-332, sobre o mito de Héracles e a Esfinge.

(9) $\mathrm{CTH} 345, \S 33, \mathrm{~B}$ । 29-41 (CTH refere-se à numeração dos textos anatólicos seguida por Laroche 1971).

(10) Th. 507-522.

(11) Op. 663-669: Hesíodo reconhece que Zeus, não obstante o seu papel de juiz, pode também ser autor do mal.

(12) LLOYD-JONES, 1971: 35.

(13) LLOYD-JONES, 1971: 32, 35.

(14) Op. 1-9; cf. Op. 333-334.

(15) Op. 130-139.

(16) Op. 180 e segs.

(17) Th. 912-914.

(18) Th. 780-806. 
(19) Th. 901 e segs.

(20) O Canto da Libertação, §4, II 1-8 (HOFFNER, 1998² 69). Na parábola 3 do Canto de Libertação (HOFFNER, 1998²70), os deuses são também agentes castigadores da insolência do filho para com o seu pai; assim também na parábola 6 (HOFFNER, 1998²: 71-72). Na parábola 7 (HOFFNER, 19982: 72), que conta como uma pilha de madeira amaldiçoa o empilhador e como depois é amaldiçoada pelo empilhador e castigada (depois se dizendo que a pilha de madeira é um homem e o empilhador o seu mestre), o agente a que se apela para executar o castigo é Tešub.

(21) CTH 324 A Ro. I 19; CTH 671 §9 Rev. 11-17.

(22) Cf. BRYCE 2002 141, com trad. de excerto do texto CTH 372 (Introdução à Oração ao deus Sol), onde se pode ver o deus Sol apelidado de «meu senhor, justo senhor do julgamento, rei do Universo".

${ }^{(23)}$ Não é isto o mesmo que dizer que é pressuposto do mito anatólico a soberania humana ser a ordem certa, como uma vez disse lapidarmente W. Burkert acerca do mito grego: "Que a soberania do homem é a ordem certa, é um pressuposto do mito grego" (BURKERT, 1991 24).

(24) BECKMAN, 2002: 37: «In parallel fashion, the chief wife of the Hittite king was associated with a solar figure, the Sun-goddess of the city of Arinna, at least to the extent that each deceased queen was represented in a temple by an image of this deity", BECKMAN, 2002: 40-41.

(25) CTH 360 .

(26) Op. 6.

(27) CTH 360, §1, 1 । 1-6.

(28) GURNEY, 1954: 139. Cf. COLLINS, 2007: 175, sobre Ištanu, o deus Sol do céu.

(29) Op. 267-269.

(30) Th. 613. Não obstante esta omnisciência divina, Zeus é enganado por Prometeu, impedindonos de concluir rotundamente que o supremo deus grego não pode ser iludido; esta aparente contradição, bem sublinhada por Werner Jaeger, é justificada e de certo modo relevada por $\mathrm{H}$. Lloyd-Jones com a argumento de que Hesíodo mistura concepções humanas e sobre-humanas, divinas, em Zeus (cf. LLOYD-JONES: 1971: 82-83).

(31) WEST, 1999: 319-324, com aproximações da justiça de Zeus, especialmente de Op. 202-285, a textos sumérios, bíblicos, egípcios e indianos.

(32) Op. 256-262.

(33) Op. 274-276.

(34) Th. 108-114.

(35) Cf. LIDDELL - SCOTT, 1996 s.v. timê.

(36) Sobre paralelos desta distribuição de competências/honras por parte de Zeus com textos sumérios, bíblicos e babilónios, ver West, 1999 304-305.

(37) LESKY, 1955 35-52 apud PINHEIRO. FERREIRA, 200510.

(38) Cf. VERNANT, 1987 124-128.

(39) CTH 364, §1.1; cf. HOFFNER, 1998: 110, Glossary, s.v. e FRIEDRICH, 1991, 53, s.v.

(40) No entanto, o tema da justiça terrena tem expressão, por exemplo, na epopeia de Kirta (KTU 1.16 VI 33-34, 44-50). 
(41) Ugarítico tpțn; KTU 1.3 V 32, 1.4 IV 44 (KTU refere-se à numeração dos textos ugaríticos seguida em DIETRICH, LORETZ, SANMARTIN: 1995).

(42) Ugarítico tpt nhr, KTU 1.2। 7, 17, 22, 26, 28, 30, 34, 41, 44, 45-46, III 7, 9, 16, 21, 22, 23, IV $15,16-17,22,25,27,30$.

(43) Cf. RAHMOUNI 2008 316-317. A proximidade semítico-semântica de "juiz" e de "rei» poderia ter confirmação posterior no texto bíblico, por exemplo em Is 33, 22: «Porque o Senhor é o nosso juiz (šof ${ }^{e} t$ tnû), o Senhor é o nosso legislador, o Senhor é o nosso rei (mâtkánû)", casos estes também pronominados (-nû), como sucede como o ug. tpt-n.

(44) Cf. RAHMOUNI 2008 314-315.

${ }^{(45)}$ Cf. Th. 780 e segs., sobre o juramento que Íris traz num cântaro de ouro, do rio sagrado e braço de Oceano.

(46) Ugarítico zbl ym; KTU 1.2 III 8, 16, 21, 23, IV 7, 14, 16, 22, 24-25, 29.

(47) KTU 1.1 IV 20, KTU 1.3 III 38-39, KTU 1.4 II 34, VI 12, VII 3-4.

${ }^{(48)} A$ associação do supremo rei divino à justiça tem paralelo no acometimento da função judicial ao rei, no âmbito terreno, facto registado também na área semítica pós-ugarítica (cf. $1 \mathrm{Sm} \mathrm{8,5}$ e segs. e FALK, 1960: 72-74).

(49) Th. 1-4.

(50) Cf. Th. 71-74.

(51) Th. 458 .

(52) E. g. Op. 158, 239. Por vezes traduzido como "filho de Crono".

(53) BURKERT, 1985: 17.

${ }^{(54)}$ CALDWELL, 1989: 72-73.

(55) LLOYD-JONES, 1971: 32-33.

${ }^{(56)} \mathrm{CTH} 364, \S 1.2$.

(57) CTH 364, §§ 3.2-3.3.

${ }^{(58)} \mathrm{CTH} 364, \S \S 5.1-5.2$.

(59) $\mathrm{CTH} 348, \S 9.3$.

(60) CTH 345, § 6 A II 1-8.

(61) GURNEY, 1954: 190.

(62) SMITH, 2001: 39.

(63) OLMO LETE, 1981: 64.

${ }^{(64)}$ Leitura possivel a partir de KTU 1.1 IV 23.

(65) OLMO LETE, 1981: 98-99.

(66) KTU 1.2 । 3-10; OLMO LETE, 1981: 109.

(67) KTU 1.1 IV 23 e segs.

(68) KTU 1.3 III 23-28; cf. MOOR, 2003: 126 e GIBSON, 1977: 9.

(69) KTU 1.4 VII 49-52; cf. MOOR, 2003: 127 e GIBSON, 1977: 7. Cf. ainda RAMOS, 1996-1997: 34: "Os temas espelhados na sua literatura mítica [de Ugarit] são grandes questões de sobrevivência para a própria sociedade, nomeadamente a produtividade dos humanos, dos animais e 
da natureza e o adequado exercício do poder, cujas vicissitudes se repercutem imediatamente sobre toda a produtividade, desde a social até à cósmica".

(70) SMITH, 2001: 128-129.

(71) KTU 1.4 VII 14-25.

(72) KTU 1.4 VII 39; ugarítico dmrn, derivado da raiz $d m r$, "ser forte", e do sufixo - $n$; cf. Rahmouni, 2008: 47-48.

(73) Ugarítico b\% 'ars.

(74) KTU 1.17। 15-26.

(75) KTU 1.17 । $34-1.17$ II 8.

(76) KTU 1.15 ॥ 11-21.

(77) MOOR 2003145.

(78) KTU 1.14 III 46-49, V 42-43.

(79) KTU 1.14 V 42-43, VI 12-13.

${ }^{(80)}$ KTU $1.16 \mathrm{~V} 10$ e segs.

(81) KTU 1.14 । 41, KTU 1.4 IV 39.

(82) Ugarítico 'ab 'adm; KTU 1.14 I 37, 43, III 32, III 47, V 43, VI 13, 31-32.

(83) Ugarítico bny bnwt; KTU 1.4 II 11, III 32, KTU 1.6 III 5, 11, KTU 1.17 I 24. A preponderância de llu surge também de forma vincada no mito ritual Os Deuses Adornados e Formosos (KTU 1.23), em que não há qualquer referência a Ba'lu e em que a fertilidade de llu salta à vista.

${ }^{(84)}$ KTU 1.1 IV 13 e segs. Também o mitema do Combate de Ba\%lu e os Deuses do Deserto pode ser considerado um conflito entre llu e Ba'lu.

${ }^{(85)}$ KTU 1.4 I 1 e segs.

(86) CAQUOT, SZNYCER, HERDNER, 1974: 62-68. Para J. C. de Moor, "Although llu is still the head of the pantheon in the Myth of Ba'lu, his power is eroding. Surely he is still the "King" $(m / k)$ and "Lord of the Gods" ('adn 'ilm). He is still called the bny bnwt, the "Creator of Creatures", or, translated more literally, "Builder of Things Built", as well as 'il mlk dyknnh "Ilu, the King who had created him (= Ba'lu)". But whereas in the Legend of Kirtu llu creates a new creature to heal his protégé, llu creates nothing new anymore in the Myth of Ba'lu. He is also no longer called 'ab 'adm "father of mankind", as in the Legend of Kirtu. llu has become a remote god who resides far away at the horizon of the habitable world where he supposedly keeps the cosmic waters under control, but he does not take an active part in ruling the world anymore. This task he has delegated to younger gods whom he appoints one after the other as viceroys on earth." (MOOR, 2003: 122-123).

(87) Posição de U. Cassuto apud CAQUOT, SZNYCER, HERDNER, 1974: 62-68.

(88) Tese de M. H. Pope apud CAQUOT, SZNYCER, HERDNER, 1974: 62-68.

${ }^{(89)}$ A leitura analógica de M. H. Pope aproxima o Ciclo de Ba'lu também da História Fenícia de Fílon de Biblos.

${ }^{(90)}$ Leituras de Werner Schmid, de Gray e de Caquot, Sznycer, Herdner; cf. CAQUOT, SZNYCER, HERDNER, 1974: 62-68.

(91) KTU 1.1 III 16. 
(92) Ugarítico 'ab šnm; KTU 1.1 III 24, KTU 1.2 । 10, III 5, KTU 1.3 V 8, KTU 1.4 IV 24, KTU 1.5 VI 2, KTU 1.6 I 36, KTU 1.17 VI 49.

(93) Ugarítico 'ad, ocorrendo enfaticamente em 'ad 'ad; KTU $1.2332,43$.

(94) KTU 1.12 । 9.

(95) «El's role as father and Athirat's as mother are often emphasized. Yet divine children are themselves fathers and mothers in the divine household. Proper names attribute fatherhood not only to El but also to Athtar, Baal, Ea, Kothar, Rapiu, and Resheph" (SMITH, 2001: 59-60); sobre a valorização do patronímico em Ugarit ver PARDEE, P. BORDREUIL, 1992: 713.

${ }^{(96)}$ Cf. RAHMOUNI, 2008: 19.

(97) KTU 1.18 6-14.

(98) Ugarítico bn dgn; KTU 1.2 I 19, 35, 37, KTU 1.5 VI 23-24, KTU 1.6 I 6, 52, KTU 1.10 III 12, 14, KTU 1.12 I 39, I 25, KTU 1.14 II 25, IV 7.

(99) Ugarítico httk dgn; KTU 1.10 III 34.

(100) Ugarítico bny bnwt; KTU 1.4 II 11, III 32, KTU 1.6 III 5, 11, KTU 1.17 I 24.

(101) Ugarítico qnyt 'ilm; KTU 1.4 I 22, III 26, 30, 35, IV 32, KTU 1.8 II 2.

(102) CAQUOT, SZNYCER, HERDNER, 1974: 52-54; Para G. del Olmo Lete, n'O Ciclo de Ba'lu, parece haver uma fusão de dois esquemas teonímicos, dois "sistemas de nomenclatura": o sistema canaanaico Dagãnu-Ba'lu e o sistema amorreu II-u-Haddu, em que os dois pares serão correspondentes, tratando-se das mesmas entidades míticas, ainda que sob nome diferentes (OLMO LETE, 1981: 70).

(103) KTU 1.4 IV-V.

(104) KTU 1.12 । 28-30.

(105) Olmo Lete, 1981: 478.

(106) KTU 1.1 III 23, 1.2 III 5, 1.3 V 8, 1.4 IV 24, 1.5 VI 2, 1.6 I 36, 1.17 VI 49.

(107) KTU 1.3 V 32, 1.4 IV 43.

(108) OLMO LETE, 1981: 68.

(109) RAMOS, 1996: 2, 34.

(110) KTU 1.24 2-3, 17 e 24.

(111) Aliás, a ideia de diversidade de tronos divinos no âmbito ugarítico sai reforçada com o caso de Môtu, divindade que também tem um trono próprio, que é, por assim dizer, o seu domínio próprio; cf. KTU 1.238 8.9.

(112) $\mathrm{CTH} 343, \S 5$, A II 8-27; nota-se aqui o paralelismo com o descrito n'As Bacantes de Eurípides (141 e segs.) (PEREIRA, 1998: 45).

(113) CTH $343, \S 9$ e segs., A III 39 e segs.

(114) Th. 969-971.

(115) Th. 453-454.

(116) Op. 379-380. 


\section{Bibliografia}

Gary BECKMAN (2002), “"My Sun-God”. Reflections of Mesopotamian Conceptions of Kingship among the Hittites", in A. Panaino e G. Pettinato, Ideologies as Intercultural Phenomena, Proceedings of the Third Annual Symposium of the Assyrian and Babylonian Intellectual Heritage Project Held in Chicago, USA, October 27-31, 2000. Milano: Università di Bologna.

Trevor BRYCE (2002), Life and Society in the Hittite World. Oxford: University Press.

Walter BURKERT (1985), Greek Religion, Archaic and Classical. Oxford: Blackwell Publishing. Walter BURKERT (1991), Mito e Mitologia. Lisboa: Edições 70.

Richard CALDWELL (1989), The Origin of the Gods, A Psychoanalytic Study of Greek Theogonic Myth. New York, Oxford: Oxford University Press.

André CAQUOT, Maurice SZNYCER, Andrée HERDNER (1974), Textes Ougaritiques, tome I, Mythes et Légendes. Paris: Les Éditions du Cerf.

B. J. COLLINS (2007), The Hittites and their World. Atlanta: Society of Biblical Literature.

Manfried DIETRICH, Oswald LORETZ, Joaquin SANMARTIN (eds.) (1995), The Cuneiform Alphabetic Texts : from Ugarit, Ras Ibn Hani and other places (KTU). Münster: Ugarit-Verlag.

Zeev W. FALK (1960), «Two symbols of justice», Vetus Testamentum 10, 1 (Jan. 1960), 72-74.

Johannes FRIEDRICH (1991), Kurzgefaßtes Hethitisches Wörterbuch. Heidelberg: Carl Winter Universitätsverlag.

J. C. L. GIBSON (1977), Canaanite Myths and Legends. London - New York, T \& T Clark International.

O. R. GURNEY (1954), The Hittites. Harmondsworth: Penguin Books.

Harry A. HOFFNER (1998²), Hittite Myths. $2^{\mathrm{a}}$ ed., Atlanta, Georgia: Scholar Press.

E. LAROCHE (1971), Catalogue des Textes Hittites, Études et Commentaires. Paris: Klincksieck.

A. LESKY (1955), "Griechischer Mythos und Vorderer Orient», Saeculum 6, 35-52.

H. G. LIDDELL, R. SCOTT (1996), A Greek-English Lexicon. Oxford: Clarendon Press.

Hugh LLOYD-JONES (1971), The Justice of Zeus. Berkeley, Los Angeles, London: University of California Press.

J.C. de Moor (2003), "Theodicy in the texts of Ugarit", in Antti Laato e Johannes C. de Moor (eds.), Theodicy in theWorld of the Bible. Leiden, Boston: Brill.

G. del OLMO LETE (1981), Mitos y Leyendas de Canaan, Segun la Tradicion de Ugarit. Madrid: Ediciones Cristiandad.

D. PARDEE, P. BORDREUIL (1992), «Ugarit: Texts and Literature», in D. N. Freedman (ed.), The Anchor Bible Dictionary, vol. 6, New York: Doubleday.

Maria Helena Rocha Pereira (1998), Euripides, As Bacantes, trad., Lisboa: Edições 70.

Ana Elias PINHEIRO, José Ribeiro FERREIRA (2005), Hesiodo, Teogonia, Trabalhos e os Dias, trad., Maria Helena da Rocha Pereira (intr.). Lisboa: Imprensa Nacional - Casa da Moeda.

Aicha RAHMOUNI (2008), Divine Epithets in the Ugaritic Alphabetic Texts. Leiden, Boston: Brill.

José A. RAMOS (1996), Baal: Caricatura e Mito, Sumário para uma lição de sintese integrada nas provas de agregação requeridas à Universidade de Lisboa. Lisboa. 
José A. RAMOS (1996-1997), Ugarit: Mitologia para uma Cidade. Lisboa: Universidade Autónoma de Lisboa.

Mark SMITH (2001), The Origins of Biblical Monotheism, Israel's Polytheistic Background and the Ugaritic Texts. Oxford, University Press.

Jean-Pierre VERNANT (1987), Origens do Pensamento Grego. Lisboa: Teorema.

Paul VEYNE (2008), Como se Escreve a História. Lisboa: Edições 70.

L. WEST (1999), The East Face of Helicon, West Asiatic Elements in Greek Poetry and Myth. Oxford: Clarendon Press. 